\title{
Tungiasis, un souvenir del viajero
}

\section{Tungiasis, a traveler's souvenir}

\section{Edgar Meneses Díaz ${ }^{1}$, Eliana Pavón ${ }^{1}$, María Eugenia Bagalá2, Laura Cortés ${ }^{3}$, Natalia Sacco $^{2}$ y Federico Pastore $^{3}$}

\section{RESUMEN}

La tungiasis es una ectoparasitosis causada por la pulga hematófaga Tunga penetrans.

Se considera una de las enfermedades dermatológicas más comunes de los viajeros que visitan áreas tropicales. El ser humano es un hospedero accidental.

Afecta exclusivamente la piel. Las lesiones suelen localizarse en los pies y sus manifestaciones clínicas son polimorfas. El diagnóstico es clínico y el tratamiento consiste en la extracción del parásito. En algunos casos es necesario agregar tratamiento con antibióticos, antiparasitarios sistémicos y profilaxis antitetánica.

Palabras clave: Tunga penetrans, tungiasis.

Dermatol. Argent. 2020, 26 (2): 68-72

\begin{tabular}{|c|c|}
\hline ABSTRACT & \\
\hline $\begin{array}{l}\text { Tungiasis is an ectoparasitosis caused by the blood-sucking flea Tunga } \\
\text { penetrans. } \\
\text { It is considered one of the most common dermatological diseases of } \\
\text { travelers visiting tropical areas. The human being is an accidental host. } \\
\text { Exclusively affects the skin. The lesions are generally located on the } \\
\text { feet and their clinical manifestations are polymorphic. The diagnosis }\end{array}$ & $\begin{array}{l}\text { is clinical and the treatment consists of the complete extraction of the } \\
\text { parasite. In some cases it is necessary to add treatment with antibiotics, } \\
\text { systemic dewormers and tetanus prophylaxis. } \\
\text { Key words: Tunga penetrans, tungiasis. } \\
\text { Dermatol. Argent. } 2020,26 \text { (2): } 68-72\end{array}$ \\
\hline
\end{tabular}

1 Médicos de la Carrera de Especialista en Dermatología

${ }^{2}$ Médica Dermatóloga

${ }^{3}$ Médico de Planta

Servicio de Dermatología, Hospital General de Agudos Dr. Enrique Tornú, Ciudad Autónoma de Buenos Aires, Argentina
Contacto del autor: Edgar Yamith Meneses Díaz

E-mail: menesesdiaz85@gmail.com

Fecha de trabajo recibido: $1 / 6 / 2020$

Fecha de trabajo aceptado: 25/6/2020

Conflicto de interés: los autores declaran que no existe conflicto de interés.

\section{INTRODUCCIÓN}

La tungiasis es una endozoonosis causada, en la mayoría de los casos, por la hembra grávida de la pulga Tunga penetrans, que provoca una ectoparasitosis transitoria en el ser humano luego de la penetración transcutánea. La pulga, según la región geográfica, recibe diferentes denominaciones como: pulga de la arena, bicho do pe, pique, pulga excavadora, bicho de cachorro, migos, jatecuba, tomasico, ton, chego, jigger ${ }^{1,2}$.

Hay referencias de infestaciones por Tunga penetrans desde 1492, cuando la tripulación de la nave Santa María, de Cristóbal Colón, la contrajo en las playas de Haitín ${ }^{2,3}$. Se la considera una enfermedad endémica de América Central, del Sur y el Caribe. 
La tungiasis y la larva migratoria son las enfermedades que más afectan a los turistas que visitan áreas tropicales y playas de América Central, del Sur, del Caribe y del océano Índico. Por este motivo, es imprescindible conocer las características clínicas de la entidad, para realizar un diagnóstico y un tratamiento adecuados $^{4}$.

\section{SERIE DE CASOS}

\section{Caso clínico 1}

Un varón de 31 años, sin antecedentes patológicos, presentó una dermatosis muy pruriginosa en los miembros inferiores y los glúteos, de 40 días de evolución y que apareció durante un viaje turístico a Brasil. Clínicamente se apreciaban pápulas redondeadas, de 5 a $15 \mathrm{~mm}$ de diámetro, algunas con un centro oscuro y costras hemáticas, rodeadas por un halo eritematoso. En las caras interna y externa de ambos pies presentaba ampollas tensas de contenido seroso, de 1 a $3 \mathrm{~cm}$ de diámetro (Fotos 1, 2 y 3).

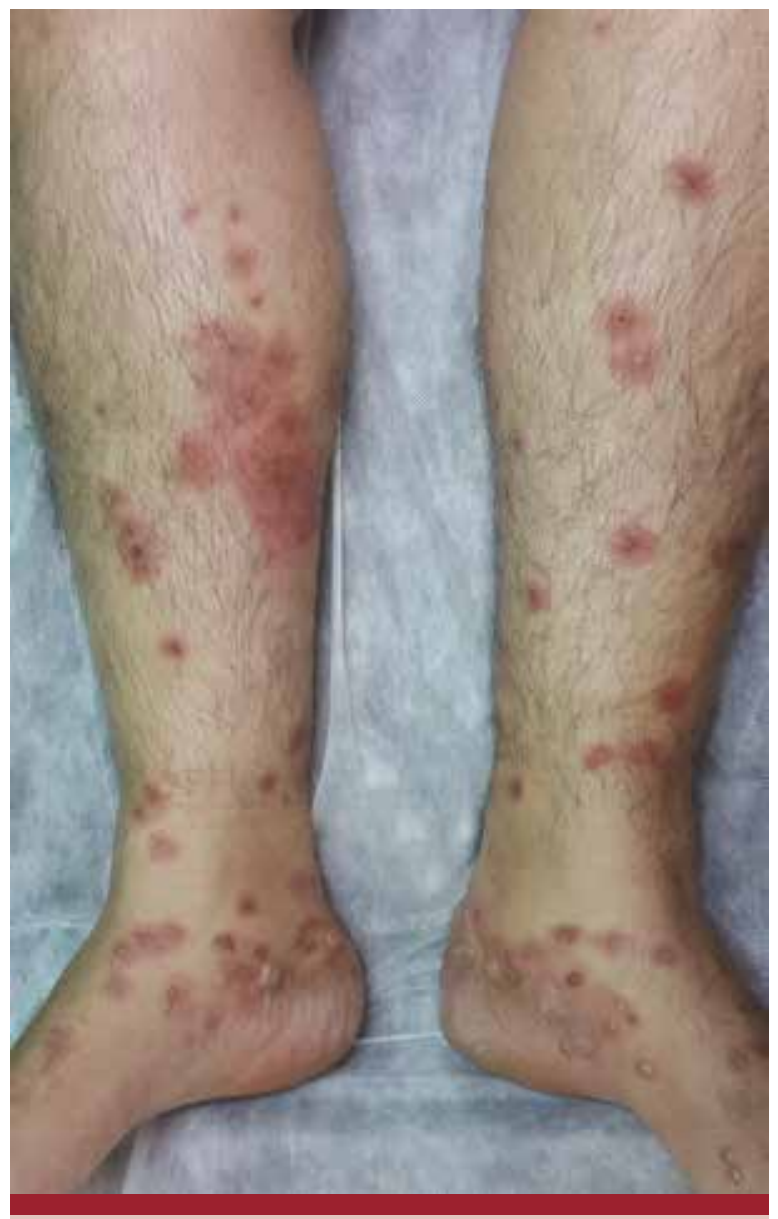

FOTO 1: Pápulas redondeadas de 5 a $15 \mathrm{~mm}$ de diámetro, algunas con un centro oscuro y costras hemáticas, rodeadas por un halo eritematoso, localizadas en ambos miembros inferiores.

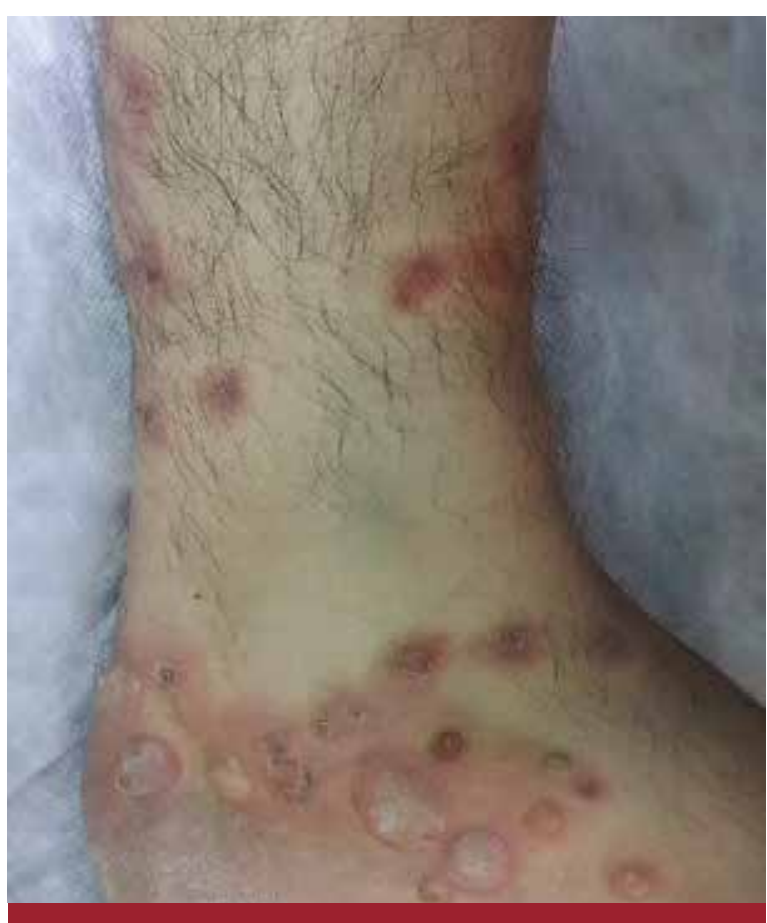

FOTO 2: Ampollas tensas de contenido seroso, de 1 a $3 \mathrm{~cm}$ de diámetro y pápulas redondeadas con una costra hemática central.

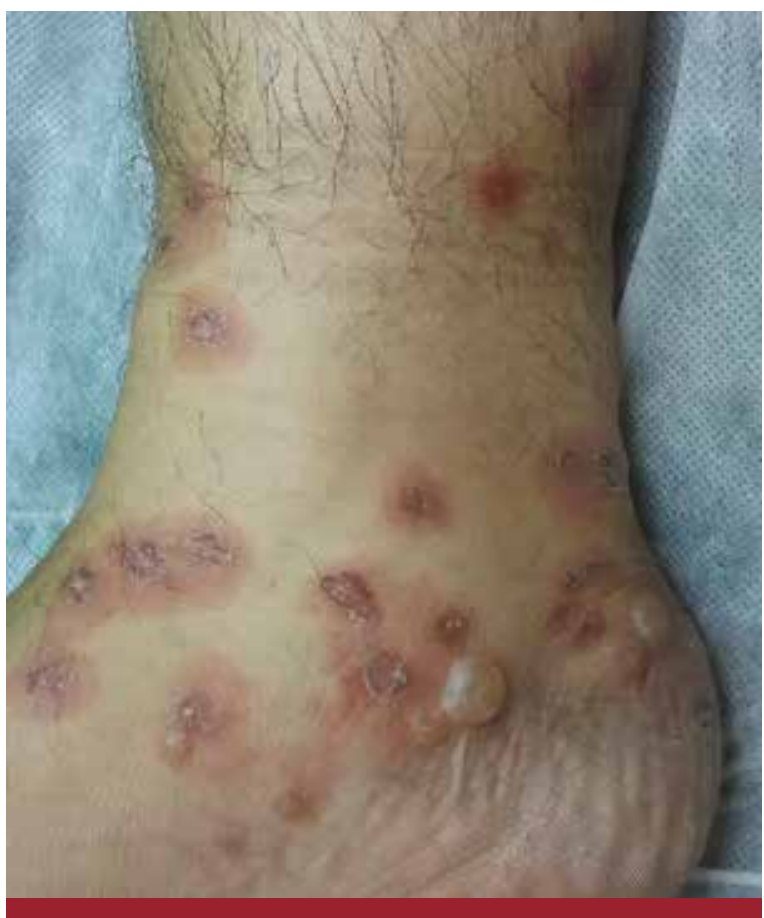

FOTO 3: Ampollas tensas de contenido seroso y pápulas redondeadas con costras hemáticas, rodeadas por un halo eritematoso.

\section{Caso clínico 2}

Una mujer de 40 años, sin antecedentes patológicos personales, consultó por una dermatosis intensamente pruriginosa localizada en ambos pies y el tercio 
medio de las piernas, que apareció luego de un viaje a la selva misionera en la Argentina. En el examen físico se observaban múltiples pápulas eritematosas, de 3 a $5 \mathrm{~mm}$ de diámetro, algunas centradas por un punto negro (Fotos 4 y 5 ).

En el examen dermatoscópico se evidenció una estructura asimétrica con un anillo marrón y orificio central, un velo negro azulado en la periferia y un halo hipercrómico circundante (Foto 6).

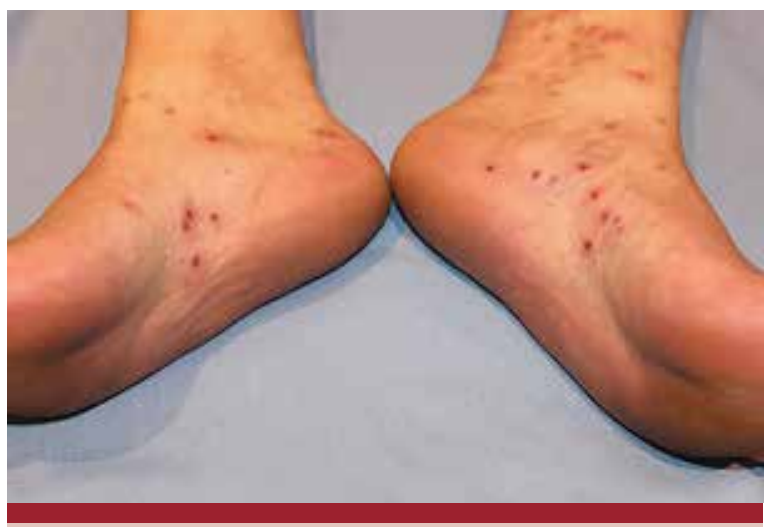

FOTO 4: Pápulas redondeadas, algunas con un centro oscuro y costras hemáticas, rodeadas por un halo eritematoso en la cara interna de ambos pies.

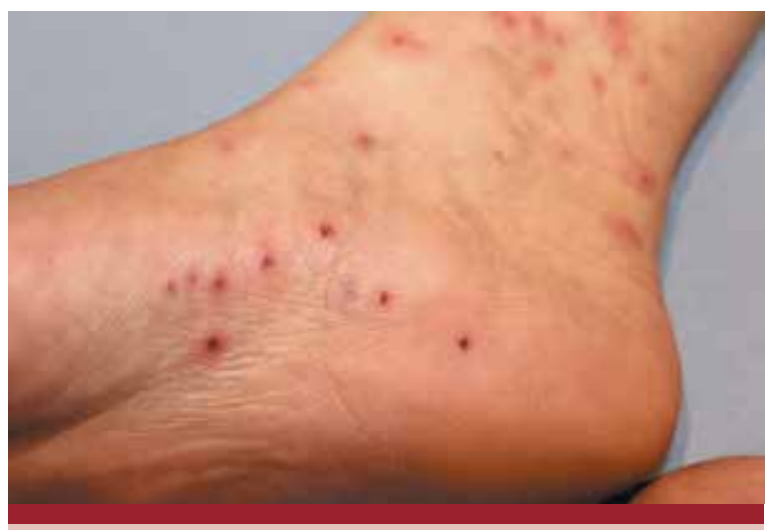

FOTO 5: Pápulas eritematosas, de 3 a $5 \mathrm{~mm}$ de diámetro, algunas centradas por un punto negro.

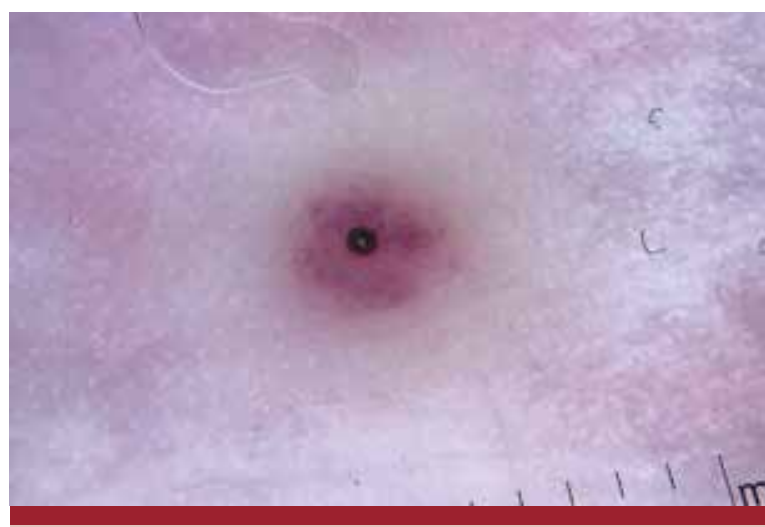

F0T0 6: Dermatoscopia. Estructura asimétrica con anillo marrón y orificio central, con velo negro-azulado en la periferia y halo hipercrómico circundante.
En ambos casos se extrajo manualmente la pulga con una aguja estéril y se indicó antibioticoterapia tópica, ivermectina $12 \mathrm{mg}$ en monodosis y profilaxis antitetánica.

\section{COMENTARIOS}

La tungiasis es una ectoparasitosis endémica exclusiva de las áreas tropicales. Es causada por la penetración de la pulga hematófaga en la piel del hospedero. Tunga penetrans es la aislada con mayor frecuencia, seguida de Tunga trimamillata, en menor proporción. Esta última se localiza en Ecuador y Perú ${ }^{1,5}$. Solo estas dos especies, de las 10 conocidas, pueden afectar al hombre o a los animales domésticos ${ }^{6}$.

Originaria de América Central, del Sur y del Caribe, se extendió a Madagascar, África subsahariana, Pakistán, costa oriental de la India y océano Índico ${ }^{7,8}$. En las áreas endémicas, la prevalencia es de 15-55\%. En la República Argentina, se encuentra en las regiones del noroeste, noreste y parte de la Mesopotamia ${ }^{4-7}$.

El hábitat natural de Tunga penetrans es el suelo arenoso, seco y sombreado. Sus principales hospederos son los perros, gatos, cerdos y ratas. El más afectado es el perro, con una tasa de infestación de hasta el $62 \%$ y las lesiones se ubican principalmente en las patas y el hocico ${ }^{9,10}$.

La tungiasis se relaciona con niveles altos de pobreza y la Organización Mundial de la Salud la incluyó en el grupo de "enfermedades tropicales desatendidas o neglectas" ${ }^{\text {. }}$ La vulnerabilidad social de las personas con bajos ingresos, el hacinamiento, las malas condiciones higiénicas y la presencia de animales domésticos, que padecen y amplifican la enfermedad, crean el ambiente propicio para su adquisición y propagación ${ }^{10}$.

En relación con los factores del hospedero, no existe predilección por sexo, raza ni edad. Sin embargo, los ancianos y los niños son los más afectados debido a su menor capacidad de autocuidado, en especial estos últimos, por la falta de uso de calzado ${ }^{11}$.

El ciclo de vida del parásito es de alrededor de un mes y consta de cuatro estadios biológicos: huevo, larva, pupa y adulto. Los huevos, depositados en el suelo, eclosionan a los 3 o 4 días. Después de 2 semanas la larva forma un capullo y atraviesa el estadio de pupa o ninfa para convertirse posteriormente en la pulga adulta y así completar su ciclo vital.

La pulga macho, tal como ocurre con Sarcoptes scabiei var. hominis, muere después de la copulación y la hembra fecundada penetra la piel del hospedero hasta la dermis papilar, alimentándose de la sangre de los capilares. Su tamaño aumenta durante un lapso de 
7 a 10 días, hasta alcanzar 0,6 a $1 \mathrm{~cm}$ de diámetro y expulsa entre 100 y 200 huevos por día ${ }^{9-11}$.

La historia natural de la infestación humana por Tunga penetrans se describió en la clasificación de Fortaleza, en 2003, y consta de cinco estadios ${ }^{4-11}$ (Tabla 1).

Es una enfermedad exclusiva de la piel y sus manifestaciones clínicas dependen del estadio en que se encuentra el parásito y del componente inflamatorio que se desencadena ${ }^{4-9}$. Esa respuesta inflamatoria se debe a tres factores: la presencia de un cuerpo extraño (Tunga penetrans), la secreción de enzimas proteolíticas que produce el parásito durante su penetración en el tejido y la sobreinfección bacteriana que suele acompañar a la mayoría de los casos ${ }^{4}$.

El diagnóstico es clínico y se basa en la localización y la morfología de las lesiones de los pacientes que habitan en zonas endémicas o han viajado a ellas ${ }^{4,5,12}$.

Dado que la pulga ejecuta un salto corto, las lesiones se ubican en los pies en el $95 \%$ de los casos, con predilección por las regiones plantar, maleolar, periun-

\begin{tabular}{|c|c|c|c|c|}
\hline $\begin{array}{c}\text { Esta- } \\
\text { dio }\end{array}$ & Inicio & $\begin{array}{l}\text { Dura- } \\
\text { ción }\end{array}$ & $\begin{array}{l}\text { Signos y } \\
\text { síntomas }\end{array}$ & $\begin{array}{c}\text { Fase de } \\
\text { artrópodo }\end{array}$ \\
\hline 1 & $\begin{array}{l}\text { La pulga } \\
\text { gravídica } \\
\text { penetra en } \\
\text { el hospe- } \\
\text { dero }\end{array}$ & $\begin{array}{c}3-7 \\
\text { horas }\end{array}$ & $\begin{array}{l}\text { Leve eritema, } \\
\text { asintomática o leve } \\
\text { prurigo }\end{array}$ & $\begin{array}{l}\text { Penetración en } \\
\text { la piel }\end{array}$ \\
\hline 2 & $\begin{array}{l}24-48 \\
\text { horas } \\
\text { pospene- } \\
\text { tración } \\
\text { cutánea }\end{array}$ & $\begin{array}{c}24 \\
\text { horas }\end{array}$ & $\begin{array}{l}\text { Halo eritematoso } \\
\text { y pruriginoso, con } \\
\text { el diámetro de la } \\
\text { pulga }\end{array}$ & $\begin{array}{l}\text { Hipertrofia } \\
\text { del segmento } \\
\text { abdominal }\end{array}$ \\
\hline 3 & $\begin{array}{l}72 \text { horas } \\
\text { pospene- } \\
\text { tración } \\
\text { cutánea }\end{array}$ & $\begin{array}{l}18 \\
\text { días }\end{array}$ & $\begin{array}{l}\text { Halo blanco de } \\
\text { consistencia firme. } \\
\text { Prurito intenso, } \\
\text { sensación de cuer- } \\
\text { po extraño, dolor, } \\
\text { ardor y aumento } \\
\text { de la temperatura } \\
\text { local }\end{array}$ & $\begin{array}{l}\text { El abdomen } \\
\text { adquiere forma } \\
\text { esférica y su } \\
\text { hipertrofia es } \\
\text { máxima. } \\
\text { Eliminación de } \\
\text { huevos y heces }\end{array}$ \\
\hline 4 & $\begin{array}{l}\text { Tercera } \\
\text { y cuarta } \\
\text { semanas }\end{array}$ & $\begin{array}{c}\text { 10-14 } \\
\text { días }\end{array}$ & $\begin{array}{l}\text { La lesión se contrae } \\
\text { y se oscurece, la } \\
\text { epidermis se en- } \\
\text { grosa y se cubre de } \\
\text { costras }\end{array}$ & $\begin{array}{l}\text { La pulga deja } \\
\text { de eliminar } \\
\text { huevos y mue- } \\
\text { re. Los restos } \\
\text { del parásito son } \\
\text { expulsados }\end{array}$ \\
\hline 5 & $\begin{array}{l}\text { Quinta } \\
\text { semana }\end{array}$ & $\begin{array}{c}\text { 4-6 } \\
\text { sema- } \\
\text { nas }\end{array}$ & $\begin{array}{l}\text { Cicatriz en el estrato } \\
\text { córneo }\end{array}$ & \\
\hline
\end{tabular}

gueal, interdigital, dorso del pie y tobillo y, excepcionalmente, cualquier otra parte del cuerpo, como en los casos presentados ${ }^{1,3,12}$.

Las lesiones pueden ser únicas, escasas o múltiples. En el caso número 2, se observaron múltiples lesiones papulosas, con un hallazgo patognomónico de la infestación, que es la presencia de algunos huevos adheridos a la piel cercana a la lesión ${ }^{7,13}$.

Entre las variantes clínicas infrecuentes se incluyen la ampollar (observada en el caso 1), la costrosa, la pustulosa, la ulcerada y la verrugosa.

La dermatoscopia es una herramienta eficaz, práctica y no invasiva para el diagnóstico. Permite distinguir los anillos concéntricos pigmentados, que rodean un poro central más pálido, que constituyen el exoesqueleto del parásito y las zonas de color azul grisáceo, que corresponden a los huevos ${ }^{1,5,14}$.

La biopsia no está indicada, excepto en casos de duda diagnóstica respecto de la ubicación o la morfología atípica ${ }^{1}$.

Entre las complicaciones se destaca la sobreinfección bacteriana, casi siempre causada por Staphylococcus aureus, que puede generar úlceras, abscesos, flemones, osteomielitis, linfangitis y gangrena. También se describió la asociación con micosis profundas ${ }^{3,4,12,13}$.

El tétanos es la complicación más grave y potencialmente mortal, en especial en los niños. Se lo informó en varias zonas endémicas donde no existe una adecuada cobertura de vacunación ${ }^{3,11,13}$.

El diagnóstico diferencial incluye: verrugas plantares, miasis, picadura o mordedura de otros artrópodos, reacción a un cuerpo extraño, escabiosis, piodermitis, abscesos, tumores y larva migratoria cutánea ${ }^{4,15}$.

El tratamiento de elección es la extracción manual completa de la pulga. El procedimiento debe ser precoz. En las lesiones iniciales, se recomienda el uso de una aguja estéril para extraer el parásito y así tratar de evitar que se rompa a fin de no desencadenar una reacción inflamatoria intensa ${ }^{1,3,4,11}$. Cuando la lesión adquiere un volumen mayor, puede ser útil su extracción en bloque, con sacabocados o punch, y la electrocoagulación de la cavidad resultante para eliminar los restos de la cutícula del parásito $^{3}$. Luego del procedimiento se sugiere aplicar en la herida antibacterianos tópicos, como mupirocina al 2\% o ácido fusídico al 2\%, dos veces por día, durante 7 a 10 días ${ }^{1,3,11,15}$. Los antibióticos sistémicos por vía oral se emplean si se observan signos de infección y los utilizados son contra Staphylococcus aureus y bacterias anaerobias ${ }^{1,3}$. En casos de lesiones múltiples, algunos autores sugieren, aunque no existe información sobre su eficacia, usar tiabendazol en dosis de 25 a $50 \mathrm{mg} / \mathrm{kg} /$ día durante 5 a 10 días o ivermectina por vía oral en una dosis de $200 \mathrm{mg} / \mathrm{kg}^{3,4,11}$. 
La administración del toxoide tetánico debe indicarse a todos los pacientes no vacunados o a los que recibieron la última dosis de vacuna antitetánica con anterioridad a los 5 años ${ }^{1,3,4,16}$.

Como medidas preventivas se debe recomendar a los viajeros a zonas endémicas:

- Uso de calzado cerrado que proteja la superficie cutánea de los suelos arenosos secos ${ }^{3,16}$.

- Evitar sentarse o recostarse en sitios donde habita la pulga.

- Autoexploración diaria para detectar las lesiones incipientes.

\section{BIBLIOGRAFÍA}

1. Fich F, Del Barrio-Díaz P, Kam S, Celle V, et ál. Tungiasis, una enfermedad tropical emergente en Chile: Comunicación de tres casos clínicos importados. Rev Chil Infectol 2013;30:676-679.

2. Verdi M, Benavente D, Gentile J, Omaña S, et ál. Tungiasis. Rev Argent Dermatol 2008;89:226-233.

3. Chinchilla-Castañeda K, Domínguez-Millán RA, DomínguezZambrano A, Mercadillo-Pérez P. Tungiasis. Dermatol Rev Mex 2016;60:59-65.

4. Pulido-Pérez A, Suárez-Fernández R. Tungiasis. Piel 2014;29:495-500.

5. Coates SJ, Thomas C, Chosidow O, Engelman D, et ál. Ectoparasites: Pediculosis and Tungiasis. J Am Acad Dermatol 2020;82:551-569.

6. Redero Cascón M, Hernando Real S. Tungiasis en paciente viajera procedente del trópico. Med Clin 2020;154:376-377.

7. Kochubei A. La tungiasis. Dermatol Perú 2017;27:169-177.

8. Ganún Musri MT, Ciancio Malato R, Villa Rodríguez R, Filice Viale P. Tungiasis. Piel 2012;27:555-557.

9. Santos RP, Resende C, Duarte M, Brito C. Tungiasis: a poorlyknown diagnosis in Europe. Two paradigmatic cases from Portugal. Act Dermatovenerol Alp Pannonica Adriat 2017;26:115-117.
- Aplicar repelentes que contengan DEET (n,n-dietil-meta-toluamida) en concentraciones de 30-50\% para los adultos, y menor de $30 \%$ en los nińos a partir de los 2 meses de edad ${ }^{1,4,11}$.

También se deben incluir políticas sociales y sanitarias, como mejoras en las viviendas, pavimentación de pisos y calles, recolección de basura, educación a la comunidad y al personal de salud, control de la enfermedad en seres humanos y reservorios animales, actividades para mejorar la calidad de vida de las comunidades abandonadas en donde se produce la enfermedad ${ }^{10,11}$.

10. González A, de Villalobos C, Ranalletta MA, Coscarón M. Aspectos adaptativos y biológicos de Tunga penetrans (Linné 1758). Epidemiología en comunidades aborígenes del norte argentino. Arch Argent Dermatol 2004;54:119-123.

11. Sikka N, Siev A, Boyer R, Pourmand A. Tungiasis, a rare case of plantar inflammatory disease, a review of travelers skin lesions for emergency providers. Am J Emerg Med 2019;37:1215.e5-1215.e7.

12. Boespflug A, Perier-Muzet M, Phan A, Dhaille F, et ál. Dermatoscopia de las lesiones cutáneas no neoplásicas. EMC-Dermatología 2018;52:1-9.

13. Miller $\mathrm{H}$, Rodríguez $\mathrm{G}$. Tungiasis en población indígena del departamento de Vaupés: epidemiología, clínica, tratamiento y prevención. Biomédica 2010;30:215-237.

14. Miller H, Ocampo J, Ayala A, Trujillo J, et ál. Very severe tungiasis in Amerindians in the Amazon lowland of Colombia: A case series. PLoS Negl Trop Dis 2019;13:e0007068.

15. Leiro V, Novac V, Olivares L, Maronna E. Tungiasis inusual: forma clínica ampollar. Dermatol Argent 2010;16:344-348.

16. Pampiglione S, Fioravanti ML, Gustinelli A, Onore G, et ál. Sand flea (Tunga spp.) infections in humans and domestic animals: state of the art. Med Vet Entomol 2009;23:172-186. 